\title{
Contribution of the TGFB1 Gene to Myocardial Infarction Susceptibility
}

\author{
R.M. Barsova ${ }^{1,2}$, B.V. Titov ${ }^{1,2}$, N.A. Matveeva ${ }^{1,2}$, A.V. Favorov ${ }^{3,4}$, T.S. Sukhinina ${ }^{2}$, \\ R.M. Shahnovich², M.la. Ruda', O.O. Favorova ${ }^{1,2}$ \\ ${ }^{1}$ Pirogov Russian National Research Medical University , Moscow, ul. Ostrovitianova, 1, \\ Moscow, 117997, Russia \\ ${ }^{2}$ Russian Cardiology Scientific and Production Center, Moscow, 3-ia Cherepkovskaia ul., 15a, \\ Moscow, 121552, Russia \\ ${ }^{3}$ Vavilov Institute of General Genetics, Russian Academy of Science, Moscow, ul. Gubkina, 3, \\ Moscow, 119991, Russia \\ ${ }^{4}$ Oncology Biostatistics and Bioinformatics, Johns Hopkins School of Medicine, Baltimore, MD \\ 21205, US \\ *E-mail: olga_favorova@mail.ru \\ Received 10.02.2012 \\ Copyright $\odot 2012$ Park-media, Ltd. This is an open access article distributed under the Creative Commons Attribution License, which permits \\ unrestricted use, distribution, and reproduction in any medium, provided the original work is properly cited.
}

\begin{abstract}
Carriage frequencies of alleles and genotypes of the TGFB1 gene polymorphous loci $-\mathbf{5 0 9 C}>\mathbf{T}$ (rs1800469), 869T $>C$ (rs1982073), 915G $>C$ ( $r$ 1800471), which affect the level of cytokine TGF- $\beta 1$ production, were analyzed in the patients of Russian ethnic descent with myocardial infarction (MI) (406 cases) and in the control group of the same ethnic descent (198 controls). Significant association with MI was observed in carriage frequencies of the allele $T G F B 1^{*}-509 \mathrm{~T}(p=0.046, \mathrm{OR}=1.45,95 \% \mathrm{CI}: 1.02-2.06)$, genotypes $T G F B 1 * 869 \mathrm{~T} / \mathrm{T}$ $(p=0.0024, \mathrm{OR}=1.75,95 \% \mathrm{CI}: \mathbf{1 . 2 2 - 2 . 5 1})$, and $T G F B 1^{*} 915 \mathrm{G} / \mathrm{G}(p=0.048, \mathrm{OR}=1.76,95 \% \mathrm{CI}: \mathbf{1 . 0 5 - 2 . 9 7})$. Linkage disequilibrium analysis for these SNPs has shown that the associations revealed can be considered to be independent. A complex analysis of MI association with combinations of alleles/genotypes of said SNPs indicates their cumulative effect. An analysis of susceptibility to early-onset MI ( $\leq 50$ years old) revealed a positive association of the allele $T G F B 1 *-509 \mathrm{~T}(p=\mathbf{0 . 0 0 2}, \mathrm{OR}=\mathbf{2 . 2 4 , 9 5 \%} \mathrm{CI}: \mathbf{1 . 3 5}-\mathbf{3 . 7 1})$ and genotype $T G F B 1 * \mathbf{8 6 9 T} / \mathrm{T}(p=0.008$, $\mathrm{OR}=1.93,95 \% \mathrm{CI}$ : 1.18-3.15), as well as their additivity. An analysis of susceptibility to recurrent MI revealed an association of the genotype $T G F B 1^{*}-509 T / T(p=0.0078, O R=2.60,95 \% \mathrm{CI}: 1.28-5.28)$. The results obtained indicate the important role of the TGFB1 gene in susceptibility to MI, including early-onset and recurrent MI, in Russians.

KEYWORDS myocardial infarction; Russians; genes; allelic polymorphism; transforming growth factor $\beta 1$; TGFB1; APSampler.

ABBREVIATIONS dNTP - deoxynucleoside triphosphate; LD - linkage disequilibrium; SD - standard deviation; SNP - single nucleotide polymorphism; TGF- $\beta 1$ - transforming growth factor beta 1 ; TGFB1 - gene encoding transforming growth factor beta 1; CI - confidence interval; IHD - ischemic heart disease; MI - myocardial infarction; OR - odds ratio; PCR - polymerase chain reaction; PCR-SSP - polymerase chain reaction with sequence-specific primers; CVD - cardiovascular diseases.
\end{abstract}

\section{INTRODUCTION}

The absolute majority of cardiovascular diseases (CVD) are complex polygenic diseases. To date, a lot of CVD genetic markers have been revealed; among them a special place belongs to the genes, which encode proteins involved in the atherosclerotic process. This is also true for ischemic heart disease (IHD), which includes the myocardial infarction (MI) as one of the forms. Among these markers is the TGFB1 gene, product of which (transforming growth factor beta 1 ) belongs to the TGF- $\beta$ cytokine superfamily and functions both as a pro-atherogenic and anti-atherogenic factor. There are three single nucleotide polymorphisms of interest: rs1800469 (SNP $-509 \mathrm{C}>\mathrm{T})$ in the promoter, rs1982073 (SNP 869T $>$ C, Leu10Pro), and rs1800471 (SNP 915G>C, Arg25Pro) in the signal sequence (exon 1) [1]. All of the polymorphisms studied affect the level of TGF- $\beta 1$ production: according to the literature [2-4], allele T of the SNP $-509 \mathrm{C}>\mathrm{T}$, allele $\mathrm{T}$ of the SNP $869 \mathrm{~T}>\mathrm{C}$, and genotype $\mathrm{G} / \mathrm{G}$ of the SNP $915 \mathrm{G}>\mathrm{C}$ are associated with the higher protein plasma level.

A number of studies are dedicated to the association analysis of these SNPs with IHD or MI development; 
some of them demonstrate such an association [1, 5, 6], while some do not.

Since it was finally proved that genetic susceptibility to many polygenic diseases varies in different ethnic groups, studies should be performed in ethnically homogenous populations. No studies have been performed on the association of the SNP $869 \mathrm{~T}>\mathrm{C}$ and $915 \mathrm{G}>\mathrm{C}$ of TGFB1 gene with MI and other CVDs occurrence in Russians. Previously, we observed a positive association of MI occurrence in a smaller sampling with the allele TGFB1*-509T in combinations with the alleles/ genotypes of the SNPs of other inflammation genes, as well as a contribution of the "alternative" allele $-509 * \mathrm{C}$ to protective combinations [7]. In the present study, a search for the association of rs1800469 (SNP -509C $>\mathrm{T}$ ), rs1982073 (SNP 869T>C, Leu10Pro), and rs1800471 (SNP 915G>C, Arg25Pro) of the TGFB1 gene with MI occurrence was performed in more than 400 patients of Russian descent, as well as an analysis of haplotypes of these SNPs in healthy individuals. The distribution of alleles and genotypes of said SNPs were analyzed by a comparison of patients of different age groups and subjects of the control group, as well as groups of patients with a single and recurrent MI(s).

\section{MATERIALS AND METHODS}

For the case-control study we used blood samples from 406 patients of Russian descent with MI, with a mean age \pm standard deviation $(\mathrm{SD})-57.5 \pm 12.8$ years. 272 of the individuals were men (mean age $-53.4 \pm 11.9$ years), and 134 were women (65.6 \pm 10.3 years). The control group consisted of 198 individuals of Russian descent without CVDs in medical history. 112 of the individuals were men (mean age $-57.1 \pm 11.9$ years), while 86 were women (mean age - $63.2 \pm 14.2$ years).

MI was diagnosed according to the $2001 \mathrm{AHA} / \mathrm{ESC}$ guidelines. The subjects of the control group underwent an examination in order to exclude IHD. All of the patients (or their relatives) and the subjects of the control group gave informed consent for this study.

The extraction of DNA with a phenol-chloroform mixture was performed according to [8].

The polymorphous loci of the TGFB1 gene were analyzed using the PCR-SSP method. A DNA fragment of $283 \mathrm{bp}$ containing SNP 869T $>C$ was amplified using the allele-specific primers 5'-AGCAGCGGTAGCAGCAGCA-3' (SSP T), 5'-GCAGCGGTAGCAGCAGCG-3' (SSP C), and the common primer 5'-CT ACCTTTT GCC GGGAGACC -3 '. In the case of SNP $915 \mathrm{G}>\mathrm{C}$, a DNA fragment of 125 bp was amplified using the allelespecific primers 5'- TGGTGCTGACGCCTGGCCG-3' (SSP G), 5'-TGGTGCTGACGCCTGGCCC-3' (SSP C), and the common primer 5'-GGCGAGCCGCAGCTTGGACA-3'. All primers were designed using the Vector NT I 7.1 and Primo software [9]. The amplification mixture $(10 \mu \mathrm{l})$ contained $70 \mathrm{mM}$ Tris-HCI $(\mathrm{pH} \mathrm{9.0)}$, $20 \mathrm{mM}\left(\mathrm{NH}_{4}\right)_{2} \mathrm{SO}_{4}, 1.0 \mathrm{mM} \mathrm{MgCl}, 0.025 \%$ Tween-20, $0.025 \%$ NP-40, 5 pmole of each primer, $0.2 \mathrm{mM}$ dNTP, $0.5 \mathrm{U}$ Taq-polymerase, and 100-200 ng DNA mineral oil. Amplification program: $95^{\circ} \mathrm{C}, 5 \mathrm{~min}$. Then, 10 cycles: $95^{\circ} \mathrm{C}-1 \mathrm{~min}, 64^{\circ} \mathrm{C}-1 \mathrm{~min}, 72^{\circ} \mathrm{C}-1 \mathrm{~min}$; and 20 cycles: $95^{\circ} \mathrm{C}-30 \mathrm{~s}, 58^{\circ} \mathrm{C}-50 \mathrm{~s}, 72^{\circ} \mathrm{C}-50 \mathrm{~s}$. PCR was performed in MC16 amplifier (DNA-technology, LLC, Russia). The presence of amplified products was checked by electrophoresis in a $2 \%$ agarose gel with ethidium bromide. SNP $-509 \mathrm{C}>\mathrm{T}$ was analyzed as described in [7].

Statistical analysis. An analysis of the deviation of the observed genotype frequencies from the HardyWeinberg equilibrium and the linkage disequilibrium (LD) analysis were performed using the free Haploview 4.0 software [10]. The carriage frequencies of alleles and genotypes of single SNPs in different groups were compared by a two-sided Fisher's exact test using the free online GraphPad Instat software [11]. We used the APSampler software $[12,13]$ to identify significant associations between MI and carriage of allele/genotype combinations of said TGFB1 SNPs and to assess the level of association significance for each combination found by the general algorithm by the value of one-sided Fisher's exact test. The differences were considered significant at $p$-values $\leq 0.05$. We computed the odds ratio (OR) and its $95 \%$ confidential intervals (CI) for each allelic combination found, and we considered only those combinations, for which CI did not cross 1 .

\section{RESULTS}

The genomic typing of the polymorphous loci $-509 \mathrm{C}>\mathrm{T}$, $869 \mathrm{~T}>\mathrm{C}$ and $915 \mathrm{G}>\mathrm{C}$ of the TGFB1 gene was carried out in patients with MI and individuals without CVDs, followed by an analysis of a possible association of these SNPs with MI development. We did not observe deviations in the distribution of SNPs alleles and genotypes frequencies from the Hardy-Weinberg equilibrium in the control group. In the group of patients, SNP 869T $>C$ and $915 \mathrm{G}>\mathrm{C}$ were in the Hardy-Weinberg equilibrium, while $-509 \mathrm{C}>\mathrm{T}$ was not $(p=0.0007)$.

The carriage frequencies of alleles and genotypes of the TGFB1 gene in the patients and controls are shown in Figure 1. The allele TGFB1*-509T (as genotypes T/T and $\mathrm{C} / \mathrm{T}$ ) was more frequent in the group of patients $(p=0.046, \mathrm{OR}=1.45,95 \% \mathrm{CI}: 1.02-2.06)$ than in controls, while the genotype TGFB1*-509C/C was less frequent ( $p=0.046$, OR $=0.69,95 \%$ CI: $0.49-0.98)$. Furthermore, genotypes TGFB1*869T $/ \mathrm{T}(p=0.0024$, OR = 1.75, 95\% CI: $1.22-2.51)$ and TGFB1*915G/G $(p=0.048$, $\mathrm{OR}=1.76,95 \% \mathrm{CI}: 1.05-2.97)$ were also more frequent in 
Table. Association of myocardial infarction with carriage of alleles/genotypes of three TGFB1 SNPs

\begin{tabular}{|c|c|c|c|c|c|c|}
\hline \multicolumn{3}{|c|}{ SNPs of TGFB1 gene } & \multicolumn{2}{|c|}{$\begin{array}{c}\text { Carriers (\%)/non-carriers (\%) } \\
\text { of the combination }\end{array}$} & \multirow{2}{*}{$\begin{array}{c}p \text {-value } \\
\text { in comparison } \\
\text { of frequencies* }\end{array}$} & \multirow{2}{*}{$\begin{array}{l}\text { OR }(95 \% \mathrm{CI}) \\
\text { for reliable } \\
\text { differences }\end{array}$} \\
\hline$-509 \mathrm{C}>\mathrm{T}$ & $869 \mathrm{~T}>\mathrm{C}$ & $915 \mathrm{G}>\mathrm{C}$ & $\begin{array}{l}\text { Patients } \\
(\mathrm{N}=397)\end{array}$ & $\begin{array}{l}\text { Control group } \\
(\mathrm{N}=198)\end{array}$ & & \\
\hline \multicolumn{7}{|c|}{ Predisposing combinations } \\
\hline $\mathrm{T}$ & $\mathrm{T} / \mathrm{T}$ & $\mathrm{G}$ & $116(29.2) / 281(70.8)$ & $33(16.7) / 165(83.3)$ & 0.00048 & $\begin{array}{c}2.06 \\
(1.34-3.18)\end{array}$ \\
\hline $\mathrm{T}$ & $\mathrm{T} / \mathrm{T}$ & - & $116(29.2) / 281(70.8)$ & $33(16.7) / 165(83.3)$ & 0.00048 & $\begin{array}{c}2.06 \\
(1.34-3.18)\end{array}$ \\
\hline- & $\mathrm{T} / \mathrm{T}$ & $\mathrm{G}$ & $181(45.6) / 216(54.4)$ & $64(32.3) / 134(67.7)$ & 0.0012 & $\begin{array}{c}1.75 \\
(1.23-2.51)\end{array}$ \\
\hline $\mathrm{T}$ & - & $\mathrm{G}$ & $273(67.2) / 133(32.8)$ & $116(58.6) / 82(41.4)$ & 0.023 & $\begin{array}{c}1.45 \\
(1.02-2.06)\end{array}$ \\
\hline \multicolumn{7}{|c|}{ Protective combinations } \\
\hline $\mathrm{C}$ & $\mathrm{C}$ & $\mathrm{C}$ & $17(4.3) / 380(95.7)$ & $23(11.6) / 175(88.4)$ & 0.00097 & $\begin{array}{c}0.34 \\
(0.18-0.65)\end{array}$ \\
\hline- & $\mathrm{C}$ & $\mathrm{C}$ & $20(5.0) / 377(95.0)$ & $23(11.6) / 175(88.4)$ & 0.0036 & $\begin{array}{c}0.40 \\
(0.22-0.75)\end{array}$ \\
\hline $\mathrm{C}$ & - & $\mathrm{C}$ & $31(7.8) / 375(92.2)$ & $29(14.6) / 169(85.4)$ & 0.0061 & $\begin{array}{c}0.48 \\
(0.28-0.83)\end{array}$ \\
\hline $\mathrm{C}$ & $\mathrm{C}$ & - & $190(47.9) / 207(52.1)$ & $117(59.1) / 81(40.9)$ & 0.0062 & $\begin{array}{c}0.64 \\
(0.45-0.90)\end{array}$ \\
\hline
\end{tabular}

*For each of the three SNP, the risk allele (genotype) is shown in a darker background color than the protective allele. **Presented in decreasing order of the significance level for predisposing and protective combinations, individually.

the group of patients. Accordingly, alleles TGFB1*869C (sum of $\mathrm{C} / \mathrm{C}$ and $\mathrm{C} / \mathrm{T}$ genotypes) $(p=0.0024, \mathrm{OR}=0.57$, 95\% CI: $0.40-0.81$ ) and TGFB1*915C (sum of C/C and $\mathrm{G} / \mathrm{C})(p=0.048, \mathrm{OR}=0.57,95 \%$ CI: $0.34-0.96)$ were more frequent in the control group. Thus, carriage of the allele TGFB $1 *-509 \mathrm{~T}$, or genotype TGFB1*869T/T, or genotype TGFB1*915G/G, can be considered as risk factors for MI development. Thereby, an association of the genotype TGFB1*869T/T with MI development is 20 times more significant than for other markers.

Due to the fact that all of the SNPs above are localized in one gene, and taking into account published data for the linkage disequilibrium of the loci in this region [14-16], we analyzed the possible haplotypes of these SNPs. We used only the control group, because only in this group Hardy-Weinberg equilibrium was observed for all SNPs. Calculation of the pairwise linkage disequilibrium between SNP - 509C $>$ T, SNP 915G $>$ C, and
$869 \mathrm{~T}>\mathrm{C}$, as measured by the Haploview 4.0 software [10], revealed a weak linkage $\left(\mathrm{r}^{2}<0.05\right.$ for all pairs). Probably, the association of MI with these SNPs can be considered to be independent. It provides grounds for an analysis of the association of the alleles/genotypescombined carriage with MI development using the results of APSampler calculations (Table).

As seen from the Table, combined carriage of the allele TGFB1*-509T and genotype TGFB1*869T/T, each of which is the MI risk factor (Fig. 1A, B), leads to an increase of both the significance level $(p=0.00048)$ and OR value (2.06) relative to the carriage of each of them alone. An addition of TGFB1*915G, carriage of which wasn't associated with MI alone (Fig. 1B), to this biallelic combination maintains the $p$ and OR values unchanged, since all (TGFB1*-509T + TGFB1*869T/T) combination carriers also bear the allele TGFB1*915G. Carriage of the other two combinations (TGFB1*869T/T 

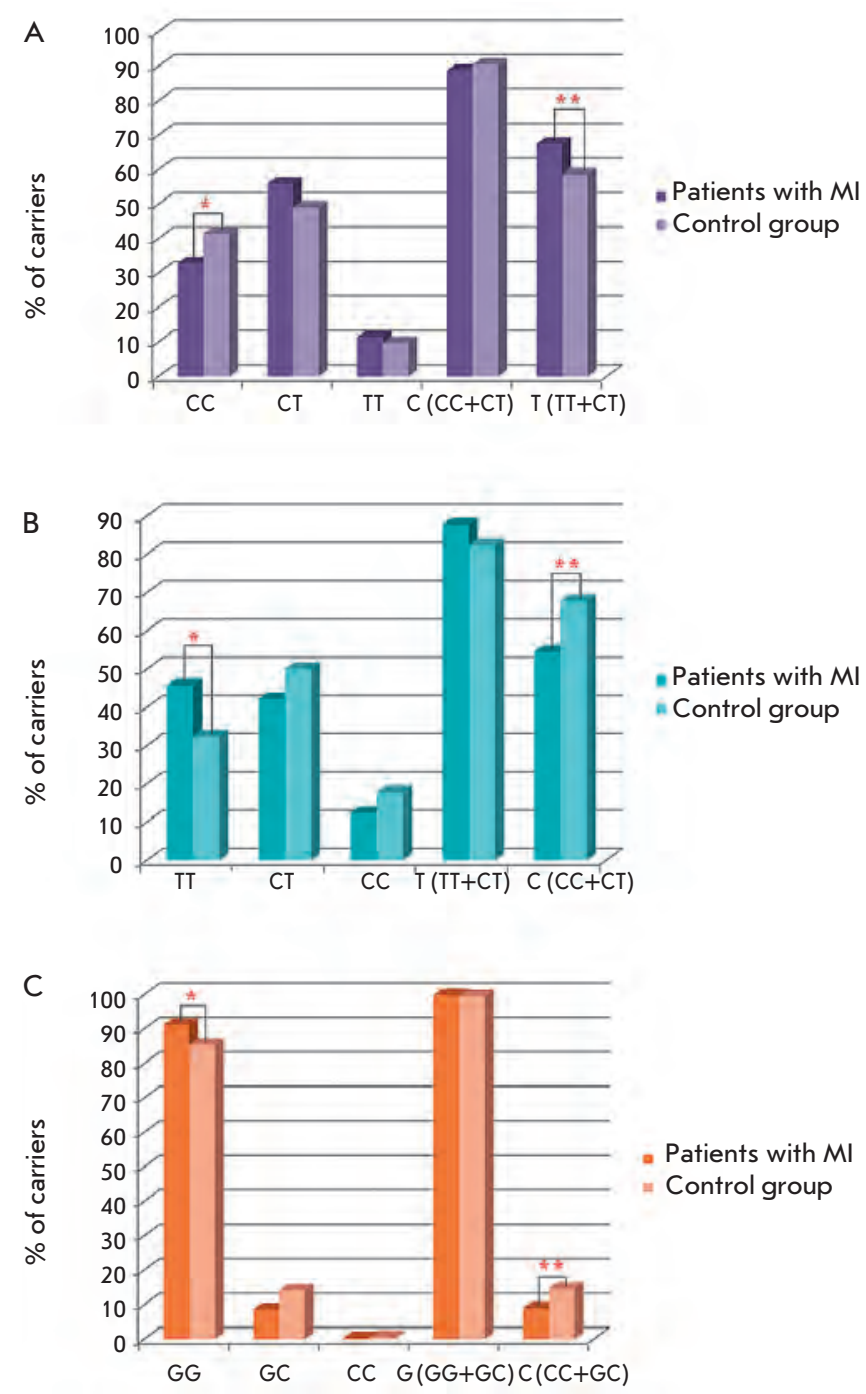

Fig. 1. Carriage frequencies of alleles and genotypes of TGFB1 gene polymorphous loci in the patients with $\mathrm{MI}$ and in the control group. (A) - SNP $-509 C>T$.

${ }^{*} p=0.046$, OR $=0.69 ;{ }^{* *} p=0.046, O R=1.45$; $(B)-$ SNP 869T $>C$. * $p=0.0024$, OR $=1.75,{ }^{*}{ }^{*} p=0.0024$, OR $=0.57 ;(C)-S N P$ 915G $>C$. * $p=0.048, O R=1.76$; ** $p=0.048$, OR $=0.57$.

+ TGFB1*915G) and (TGFB1*-509T + TGFB1*915G) is characterized by the less significance level $(p=0.0012$ and 0.023 , respectively) and OR values (1.75 and 1.45, respectively) than the combination (TGFB1*-509T + TGFB1*869T/T).

Combined carriage of the alleles TGFB1*-509C, TGFB1*869C, and TGFB1*915C is also highly significant, but it is negatively associated with MI (Table). A single negative association with MI was shown for the two latter alleles, but not for TGFB1*-509C (Fig. 1). In this case, the significance level and OR dissimilarity from 1 for the triallelic combination $(p=0.00097, \mathrm{OR}=$ 0.34 ) were higher than for all three biallelic combinations embodied ( $p 0.0036$ to 0.0062 ; OR 0.40 to 0.64 ). Furthermore, alleles/genotypes of the three SNPs included in protective combinations are alternative to the alleles included in the predisposing combination.

It is known that genetic risk factors are often more significant for MI development at a younger age (in the case of early-onset MI). On this basis, we analyzed the alleles/genotypes distribution of polymorphous loci in patients of different age subgroups with MI. By the allocation of the a subgroup of patients who had developed the MI before 50 years of age inclusive (121 individuals), comparison of them with the total control group showed differences similar to the differences in the total sample. Thus, the allele TGFB1*-509T $(p=0.002, \mathrm{OR}=2.24,95 \% \mathrm{CI}: 1.35-3.71)$ and genotype $T G F B 1 * 869 \mathrm{~T} / \mathrm{T}(p=0.008, \mathrm{OR}=1.93,95 \% \mathrm{CI}$ : $1.18-3.15)$ were more frequent in the group of patients younger than 50 , while the genotype TGFB1*-509C/C $(p=0.002, \mathrm{OR}=0.45,95 \% \mathrm{CI}: 0.27-0.74)$ and allele TGFB1*869C $(p=0.008, \mathrm{OR}=0.52,95 \% \mathrm{CI}: 0.32-0.85)$ were more frequent in the control group. Furthermore, the complex analysis revealed the combination of the allele TGFB1*-509T and genotype TGFB1*869T/T $(p=0.00015, \mathrm{OR}=2.73,95 \% \mathrm{CI}: 1.60-4.63)$, which is associated with an early-onset MI and analogous to that obtained in the total group.

Then, we divided the group of patients into subgroups of patients with first MI (73 individuals) and with recurrent $\mathrm{MI}(\mathrm{s})$ (226 individuals) and compared their genotypes with each other. We found an association with only one SNP: genotype TGFB1*-509T/T was more frequent in the group of recurrent $\mathrm{MI}(\mathrm{s})$, then in the group of patients with only one $\mathrm{MI}(p=0.0078$, OR $=2.60,95 \% \mathrm{CI}: 1.28-5.28)$, whereas allele $\mathrm{TGFB} 1^{*}-509 \mathrm{C}$ was protective $(p=0.016, \mathrm{OR}=0.38,95 \% \mathrm{CI}: 0.19-0.78)$. Combinations found by complex analysis were less significant than single association of SNP $-509 \mathrm{C}>\mathrm{T}$.

\section{DISCUSSION}

In this paper we present data on the distribution of alleles and genotypes of three functional polymorphous loci of the TGFB1 gene in a population sample of Russians (control group). We could find published data on the frequency of alleles/genotypes only for one of the SNPs studied in Russians: namely $869 \mathrm{~T}>\mathrm{C}$, notably in a group of men [17]. The genotype frequencies obtained in that study are close to the frequencies identified in the present study (Fig. 2B). Figure 2 shows data not only for Russians, but also published data on the genotype distribution of the SNP-509C $>$ T, SNP $869 \mathrm{~T}>\mathrm{C}$ and SNP $915 \mathrm{G}>\mathrm{C}$ of the TGFB1 gene in different Caucasian populations. Generally, the genotype frequen- 
cies we observed in Russians fall within a fairly wide range of frequencies, which are described for different populations of Europe. Besides, the picture varies for individual SNPs: if there is complete uniformity of genotype distribution for $915 \mathrm{G}>\mathrm{C}$ in all the Caucasian populations studied (Fig. 2C), then in the case of SNP$509 \mathrm{C}>\mathrm{T}$ and SNP $869 \mathrm{~T}>\mathrm{C}$, ethnic differences reach the significance level ( $p=0.001)$ when the genotype frequencies of $-509 \mathrm{~T} / \mathrm{T}$ in Russians and Italians are compared (Fig. 2A).

These data may reflect differences in the linkage patterns of TGFB1 polymorphous loci in different populations. Although many studies on Caucasians have revealed different haplotypes containing TGFB1 polymorphous loci, we obtained no similar data for Russians. Probably, this is due to the population-specific character of LD pattern formation, while the differences observed reflect the significant ethno-specific variability of haploblocks [18].

We have shown the contribution of the TGFB1 gene, specifically the contribution of carriage of the polymorphous loci $-509 \mathrm{C}>\mathrm{T}, 869 \mathrm{~T}>\mathrm{C}$ and $915 \mathrm{G}>\mathrm{C}$ of the TGFB1 gene, as well as their combinations to MI genetic susceptibility in Russians. The comparison of significance level and OR values for these combinations with those of individual alleles/genotypes suggests that, in case of their combined carriage, a cumulative effect occurs, which most likely reflects summation of the independent contributions of different polymorphous loci of the same gene in MI development. Since all the risk alleles/genotypes we found (TGFB1*-509T, TGFB1*869T/T and TGFB1*915G/G) are associated with the higher level of gene expression [2-4], we can assume that cumulative association is determined by the unidirectionality of changes in the TGF- $\beta 1$ protein level.

In the analysis of genetic susceptibility to early-onset MI, we observed a significant association of SNP TGFB $1^{*}-509 \mathrm{C}>\mathrm{T}$ and $869 \mathrm{~T}>\mathrm{C}$, but not for $915 \mathrm{G}>\mathrm{C}$. In the case of recurrent MIs, significant associations were observed only for SNP TGFB1*-509C $>$ T. Besides, the risk alleles were the same as for the total group of patients. Thereby, SNP $-509 \mathrm{C}>\mathrm{T}$ and $\mathrm{SNP} 869 \mathrm{~T}>\mathrm{C}$ can be considered as MI markers irrespective of age, including early-onset MI, while the SNP TGFB $1^{*}-509 \mathrm{C}>\mathrm{T}$ can serve as a predictive marker of recurrent MI development. However, we cannot exclude that the reduction in the number of associated markers in the subgroups analyzed, compared to the total group of patients, may be caused by the reduction in the size of the sample.

The associations found are in general consistent with the results obtained for other Caucasians, although it should be noted that significant variations are found in the published data. The results of study of early-onset

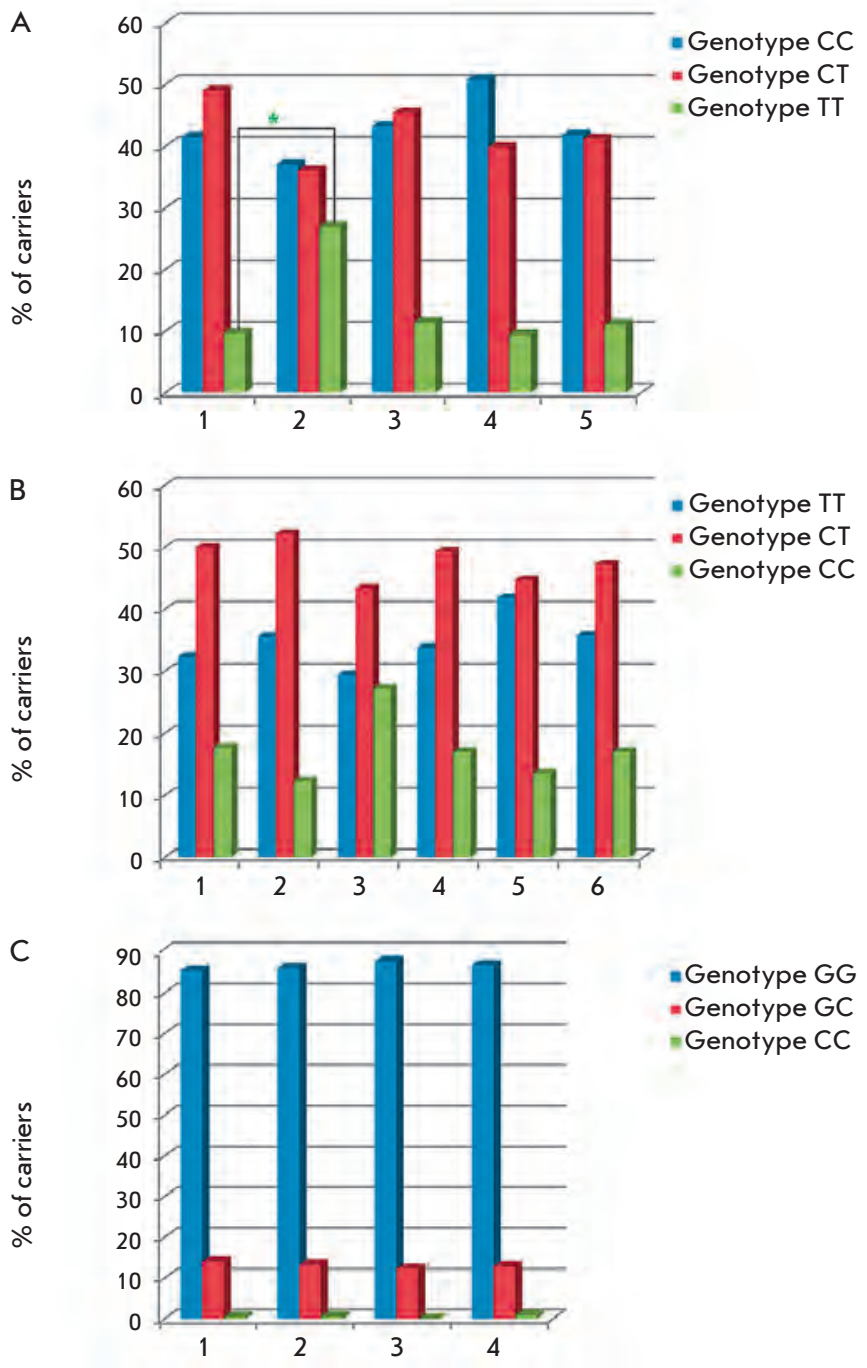

Fig. 2. Carriage frequencies of genotypes of the TGFB1 gene polymorphous loci in different Caucasian populations. (A) - SNP -509C > T. 1 - Russia, control group in the present study, 2 - Italy [6], 3 - Germany [5], 4 - UK [14], 5 - ECTIM study (France + Northern Ireland) [1]; (B) - SNP 869T>C. 1- Russia, control group in the present study, 2 - Russia, men [17], 3 - Italy [6], 4 - Germany [5], 5 - England [14], 6- ECTIM study (France + Northern Ireland) [1]; (C) - SNP 915G>C. 1 - Russia. Control group in the present study, 2 - Germany [5], 3 - UK [14], $4-$ ECTIM study (France + Northern Ireland) [1].

* $p=0.001$.

MI in Italians [6] and ECTIM study, which was performed on the French and the Northern Ireland population [1], are similar to our findings on the predisposing role of the alleles TGFB $1^{*}-509 \mathrm{~T}$ and TGFB $1 * 915 \mathrm{G}$, respectively. Our results on the positive association of the allele TGFB ${ }^{*} 869 \mathrm{~T}$ coincide with the findings for 
Germans [5], but are in contradiction with the data for Italians [6]. A number of publications have reported no significant associations of these polymorphisms with MI in Caucasians.

Cytokine TGF- $\beta 1$, which is secreted by different cell types, including blood mononuclear cells, vascular smooth muscle cells and fibroblasts, participates in the formation and remodeling of vessels, as well as in cell differentiation and migration [19]. It plays an important role in the pathogenesis of CVDs, including atherosclerosis (including IHD and MI), essential hypertension, myocardial hypertrophy and fibrotic events, leading to heart failure and restenosis after heart surgery [20].

Some studies have found that TGF- $\beta 1$ has an antiatherogenic effect: it inhibits inflammation and promotes atherosclerotic plaque stabilization. On the other hand, the high level of the TGF- $\beta 1$ associated with the stenosis of blood vessels and thrombosis [20] promotes fibrosis and inhibits endothelial regeneration [21]; i.e., it acts as a proatherogenic factor. In particular, it may contribute to early lipid spots by stimulating the formation of an extracellular matrix and inhibiting its degradation [20]. On the basis of data on the role of TGF- $\beta 1$ in atherosclerosis pathogenesis, both low and high TGF- $\beta 1$ level can be unfavorable for the development of MI, depending on the combination of other factors. One such factor may be the ethnic identity of the groups studied.

\section{CONCLUSIONS}

Our data on the association of MI with alleles/genotypes of SNP TGFB1*-509T, TGFB1*869T/T and TGFB1*915G/G, which are associated with the higher level of gene expression [2-4], may be indicative of the dominance of the proatherogenic functions of this cytokine in MI in Russians.

An aggregation of the results indicates the important role of the TGFB1 gene in the formation of susceptibility to MI in Russians. It once again shows the necessity of studying the genetic factors in each ethnic group individually.

The study was supported by grant 8/3-280n-10 of the Moscow Government.
REFERENCES

1. Cambien F., Ricard S., Troesch A., Mallet C., Generenaz L., Evans A., Arveiler D., Luc G., Ruidavets J.B., Poirier O. // Hypertension. 1996. V. 28. № 5. P. 881-887.

2. Shah R., Hurley C.K., Posch P.E. // Hum. Genet. 2006. V. 120. P. 461-469.

3. Nikolova P.N., Ivanova M.I., Mihailova S.M., Myhailova A.P., Baltadjieva D.N., Simeonov P.L., Paskalev E.K., Naumova E.J. // Transpl. Immunol. 2008. V. 18. № 4. P. 344-348.

4. Khalil M.S., El Nahas A.M., Blakemore A.I. // Nephron Exp. Nephrol. 2005. V. 101. № 2. P. e31-41.

5. Koch W., Hoppmann P., Mueller J.C., Schomig A., Kastrati A. // Arterioscler. Thromb. Vasc. Biol. 2006. V. 26. № 5. P. 1114-1119.

6. Crobu F., Palumbo L., Franco E., Bergerone S., Carturan S., Guarrera S., Frea S., Trevi G., Piazza A., Matullo G. // BMC Med. Genet. 2008. V. 9. № 13.

7. Sudomoina M.A., Sukhinina T.S., Barsova R.M., Favorov A.V., Shakhnovich R.M., Titov B.V., Matveeva N.A., Rybalkin I.N., Vlasik T.N., Ochs M.F. et al // Mol Biol (Mosk). 2010. V. 44. № 3. P. 463-471.

8. Sambrook J., Fritsch E.F., Maniatis T. // Molecular Cloning / Ed. Nolan C. Cold Spring Harbor, N.Y.; Cold Spring Harbor Lab. Press, 1989.

9. www.changbioscience.com/primo/

10. http://www.broad.mit.edu/mpg/haploview

11. http://www.graphpad.com/quickcalcs/index.cfm
12. http://code.google.com/p/apsampler/

13. Favorov A.V., Andreewski T.V., Sudomoina M.A., Favorova O.O., Parmigiani G., Ochs M.F. // Genetics. 2005. V. 171. P. 2113-2121.

14. Syrris P., Carter N.D., Metcalfe J.C., Kemp P.R., Grainger D.J., Kaski J.C., Crossman D.C., Francis S.E., Gunn J., Jeffery S., et al. // Clin. Sci. (London). 1998. V. 95. № 6. P. 659-667.

15. Grainger D.J., Heathcote K., Chiano M., Snieder H., Kemp P.R., Metcalfe J.C., Carter N.D., Spector T.D. // Hum. Mol. Genet. 1999. V. 8. № 1. P. 93-97.

16. Sie M.P., Uitterlinden A.G., Bos M.J., Arp P.P., Breteler M.M., Koudstaal P.J., Pols H.A., Hofman A., van Duijn C.M., Witteman J.C. // Stroke. 2006. V. 37. № 11. P. 2667-2671. 17. Churnosov M.I., Nekipelova E.V., Tekunova T.S., Koneva O.A., Reshetnikov E.A., Akulova L.Iu., Dobrodomova I.S., Altukhova O.B., Demin S.S. // UNID BelGU. 2008. V. 46. № 6 .

18. de Bakker P.I., Yelensky R., Pe'er I., Gabriel S.B., Daly M.J., Altshuler D. // Nat Genet. 2005. V. 37 № 11. P. 12171223.

19. Khan R., Agrotis A., Bobik A. // Cardiovasc. Res. 2007. V. 74. № 2. P. 223-234.

20. Aihara K., Ikeda Y., Yagi S., Akaike M., Matsumoto T. // Cardiol. Res. Pract. 2011. V. 2011. 175381.

21. Kim I.Y., Kim M.M., Kim S.J. // J. Biochem. Mol. Biol. 2005. V. 38. № 1. P. 1-8. 